\title{
Infective Endocarditis in the Elderly
}

\author{
Lucy Miller and Jim George \\ Department of Medicine for the Elderly, \\ Cumberland Infirmary, Carlisle, \\ U.K.
}

\section{Introduction}

In the $21^{\text {st }}$ century, despite advanced diagnostic imaging, improved antibiotic treatment, and widely available surgery, the incidence of infective endocarditis (IE) has not reduced in recent years, and continues to have high morbidity and mortality (Prendergast, 2005). Over the years there have been changes in the natural history, predisposing factors, sequelae and causative organisms. In particular, rheumatic heart disease is an uncommon predisposing factor, and now degenerative valve disease is much more common in the elderly population. As with many conditions, elderly patients with IE can present in very nonspecific ways, making diagnosis more difficult, leading to delays in treatment. IE in elderly patients is associated with a poor prognosis. Fewer patients receive valve surgery, due to higher operative risk, but this does still remain a treatment option for suitable patients. Our knowledge and understanding of endocarditis in the elderly, compared to younger patients, is predominantly influenced by important case series reports in the literature (Table 1) and these will be referred to in the text. European Guidelines are available for guidance in management of IE in all age groups (European Society of Cardiology, 2009).

\section{Epidemiology}

Elderly patients are predisposed to infectious diseases for multiple reasons; impairment of innate and adaptive immunity, increased comorbidities, increased functional limitations, increased instrumentation and implantation of prosthetic devices, and increased numbers of patients living in care homes (High et al, 2005). These factors result in an increase in adverse outcomes in the elderly. It therefore stands to reason that the incidence of IE has been shown to increase with age, and the incidence amongst elderly patients is also increasing (Dhawan, 2002). So with the ageing population, IE in the elderly is at an all time high. In the European Heart Survey, $26 \%$ of cases of IE were in elderly patients (>70 years old) (Iung et al, 2003), and in a French survey $33 \%$ of IE patients were over 67 years of age (Delahaye et al, 1999). In further French studies, the incidence of IE peaked between the ages of 70 and 80 years (Hoen et al, 2002). The risk of IE in the elderly has been found to be 4.6 times higher than in the general population. Reasons for this may include a high prevalence of undiagnosed degenerative valve disease, and again higher rates of invasive procedures and implanted devices compared to younger patients. 


\begin{tabular}{|c|c|c|c|c|c|}
\hline Author & Patients & & Clinical features & $\begin{array}{l}\text { Prosthetic devices (e.g. } \\
\text { pacemakers or valves) }\end{array}$ & Causes \\
\hline $\begin{array}{l}\text { Selton-Suty } \\
\text { et al (1997) }\end{array}$ & $\begin{array}{l}\text { Total } \\
\text { Over } 70 \\
\text { Under } 70\end{array}$ & $\begin{array}{r}114 \\
25 \\
89\end{array}$ & $\begin{array}{l}\text { Younger patients more embolic } \\
\text { complications } 28 \% \text { v } 8 \%(p<0.05)\end{array}$ & $\begin{array}{l}52 \% \text { elderly } \mathrm{v} \\
25 \% \text { young } \\
(p<0.05)\end{array}$ & $\begin{array}{l}\text { Portal of entry } \\
\text { more often } \\
\text { digestive in old } \\
\text { patients } 50 \% \mathrm{v} \\
17 \%(\mathrm{p}=0.01)\end{array}$ \\
\hline $\begin{array}{l}\text { Di Salvo } \\
\text { et al (2003) }\end{array}$ & $\begin{array}{l}\text { Total } \\
\text { Over } 70 \\
50-70 \\
\text { Under } 50\end{array}$ & $\begin{array}{r}315 \\
87 \\
111 \\
117\end{array}$ & $\begin{array}{l}\text { Clinical features similar between } 3 \\
\text { groups except anaemia less common in } \\
\text { patients under } 50 \text { years }\end{array}$ & $\begin{array}{l}\text { Pacemaker endocarditis } \\
\text { commoner in over } 70^{\prime} \text { s, } \\
\text { but prosthetic valve } \\
\text { endocarditis similar in } \\
\text { both groups }\end{array}$ & $\begin{array}{l}\text { Older patients } \\
\text { more often } \\
\text { digestive or } \\
\text { urinary portal } \\
\text { entry }\end{array}$ \\
\hline $\begin{array}{l}\text { Durante- } \\
\text { Mangoni } \\
\text { et al (2008) }\end{array}$ & $\begin{array}{l}\text { Total } \\
\text { Over } 65 \\
\text { Under } 65\end{array}$ & $\begin{array}{l}2759 \\
1056 \\
1703\end{array}$ & $\begin{array}{l}\text { Mitral valve involvement more } \\
\text { common in older people. Fewer } \\
\text { vegetations and more abscesses in older } \\
\text { patients. Vascular and immune } \\
\text { mediated phenomena, including } \\
\text { embolisation, less common in older } \\
\text { people ( } \mathrm{p}<0.001) \text {. Chronic illnesses, } \\
\text { including diabetes and cancer, } \\
\text { commoner in older people. Rate of } \\
\text { complications lower in older people. }\end{array}$ & $\begin{array}{l}\text { More commonly } \\
\text { prosthetic devices or } \\
\text { pacemakers in older } \\
\text { people }(\mathrm{p}<0.001)\end{array}$ & $\begin{array}{l}\text { MRSA, Strep } \\
\text { bovis and } \\
\text { enterococci mo } \\
\text { common in old } \\
\text { patients }\end{array}$ \\
\hline $\begin{array}{l}\text { Remadi } \\
\text { et al (2009) }\end{array}$ & $\begin{array}{l}\text { Total } \\
\text { Over } 75 \\
\text { Under } 75\end{array}$ & $\begin{array}{r}348 \\
75 \\
273\end{array}$ & $\begin{array}{l}\text { Older patients more severely ill and } \\
\text { more comorbidities. No difference in } \\
\text { embolism risk. }\end{array}$ & $\begin{array}{l}\text { Pacemakers and } \\
\text { prosthetic valve } \\
\text { endocarditis } \\
\text { significantly more } \\
\text { common in older } \\
\text { patients }(\mathrm{p}<0.001)\end{array}$ & $\begin{array}{l}\text { Similar betwee } \\
\text { older and } \\
\text { younger patien }\end{array}$ \\
\hline $\begin{array}{l}\text { Ramirez- } \\
\text { Duque et al } \\
\text { (2011) }\end{array}$ & $\begin{array}{l}\text { Total } \\
\text { Over } 65 \\
\text { Under } 65\end{array}$ & $\begin{array}{r}961 \\
356 \\
605\end{array}$ & $\begin{array}{l}\text { Comorbidity, renal failure and septic } \\
\text { shock more common in older patients }\end{array}$ & $\begin{array}{l}25 \% \text { older patients } \mathrm{v} \\
23 \% \text { young patients } \\
\text { (NS) }\end{array}$ & $\begin{array}{l}\text { Nosocomial } \\
\text { acquisition } \\
\text { commoner in } \\
\text { older patients } \\
(\mathrm{p}<0.01)\end{array}$ \\
\hline
\end{tabular}


It has been previously reported that IE in the elderly is associated with a poor prognosis and high complication rate. The onset is usually insidious, sometimes the presenting symptoms are less severe, and diagnosis is sometimes therefore delayed, as well as more aggressive pathogens causing the infection. Age has been shown to be an independent prognostic factor for in-hospital mortality (Durante-Mangoni et al, 2008).

\section{Causes}

Historically, previous rheumatic heart disease was a very common predisposing factor for IE (Prendergast, 2005). However, this is now rarely a factor. Older people are particularly prone to develop mitral annular calcium (MAC). This is a chronic degenerative process that occurs in older persons, particularly women, and often results in mitral regurgitation (Roberts and Perloff, 1972). Older people with MAC have a high incidence of atrial fibrillation and are especially at risk of developing endocarditis (Mambo et al, 1978). The avascular nature of the mitral annulus prevents antibiotics reaching the bacteria, predisposing to peri annular abscesses and a poor prognosis. Aronow et al (1990) demonstrated at follow up of 39 months a 3\% incidence of bacterial endocarditis in 526 older persons with MAC and only a $1 \%$ incidence in 450 older persons without MAC. In IE in the elderly, gastrointestinal sources of bacteria are more common. Group D streptococcus (Streptococcus bovis) is frequently implicated (Vahanian, 2003). This is associated with colonic pathology, in particular neoplasia, as well as the involvement of multiple valves and embolic complications. Enterococcus is also more common in the elderly. However, it has also been reported that vegetations in the elderly are generally smaller, with a lower embolic risk (Selton-Suty et al, 1997). Pathogens are more commonly of urinary origin as well. It is thought that this is due to the higher proportion of urethral and prostatic procedures performed in the elderly (Di Salvo et al, 2003). Pacemaker endocarditis is commoner amongst the elderly, as would be expected as the number of patients with pacemakers increases with age (Remadi et al, 2009). Pacemaker endocarditis has been associated with even more difficult and delayed diagnosis, resulting in a poor prognosis.

\section{Diagnosis}

The clinical diagnosis of IE is based on Duke criteria, which includes positive blood cultures, suggestive features on echocardiography, predisposing heart disease, fever, and vascular and immunological phenomena (Prendergast, 2005). The St Thomas modifications include serology, elevated inflammatory markers, and other clinical signs including splenomegaly, haematuria, splinter haemorrhages and rashes (Prendergast, 2005). However, the onset of IE can be acute or insidious, and the presence of classical signs as described by Duke criteria are often absent, particularly in the elderly (Vahanian, 2003). Therefore, in the presence of signs of sepsis with no obvious source, IE should always be considered in the elderly. Table 2 lists the many common presentations in older people. Overall, the elderly report fewer symptoms (Selton-Suty, 1997). Fever is less common than with younger patients, but anaemia is more common, probably due to the presence of Streptococcus bovis and colonic pathology, resulting in bleeding and anaemia. Delirium is also a more prominent feature. Murmurs are often thought to be insignificant in the elderly, so do not necessarily raise 
suspicion of IE. New or changing murmurs are heard less frequently in the elderly. Positive blood cultures remain the main diagnostic tool (Prendergast, 2005). At least three sets of cultures should be taken prior to the administration of any antibiotics, and ideally both aerobic and anaerobic cultures should be incubated. Negative cultures most frequently occur after prior antibiotic administration, but increasingly due to fastidious organisms. In particular, negative cultures occur in IE related to prosthetic valves and pacemakers, which are more common in the elderly. Transthoracic and transoesophageal echocardiography (TTE and TOE respectively) are now commonly used in the diagnosis and management of IE (Prendergast, 2005). It has been reported that the detection of vegetations in the elderly is lower with TTE, so TOE should be used as it is more sensitive and specific. In general, TTE is performed first, then TOE performed when TTE is negative, but there is a high clinical suspicion of IE. TOE has revolutionised the diagnosis of IE in the elderly by increasing the diagnostic yield by $45 \%$ (Dhawan, 2002).

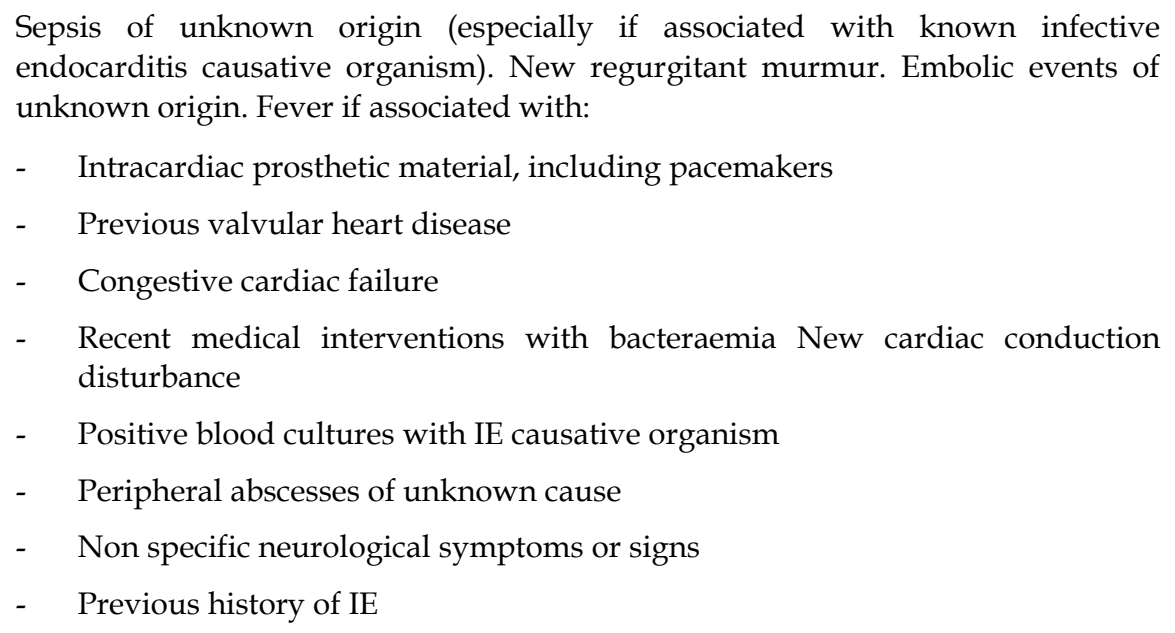

- Recent medical interventions with bacteraemia New cardiac conduction disturbance

- Positive blood cultures with IE causative organism

- Peripheral abscesses of unknown cause

- Non specific neurological symptoms or signs

- $\quad$ Previous history of IE

Table 2. Clinical presentations of infective endocarditis in the elderly

\section{Management}

Successful treatment of IE in the elderly requires close cooperation between the geriatrician, cardiologist, microbiologist, and cardiac surgeon. Regular review of the patient is required to assess for progression or development of complications (Prendergast, 2005). International guidelines have been published to provide recommendations on the treatment of IE (European Society of Cardiology, 2009). Rapid administration of antibiotics is critical in the initial management of IE (Dhawan, 2002). Antibiotics in high serum concentrations are essential to ensure penetration into the vegetations, and prolonged treatment (4-6 weeks) is required to kill dormant bacteria (Prendergast, 2005). Intravenous antibiotics as an in-patient is the preferred method, but with increasing provision for the administration of intravenous antibiotics in the community, this is becoming an increasingly popular option after the initial two week treatment period when the complication rate is highest. However, this may 
not be a suitable option in elderly patients who may require in-patient care for the full duration of treatment. Usual initial treatment is broad spectrum, with a combination of a penicillin and an aminoglycoside. In the presence of a prosthetic valve vancomycin or gentamicin is usually used, with or without rifampicin (Dhawan, 2002). There is no evidence for the use of oral antibiotics after the completion of the intravenous course (Prendergast, 2005). When IE is suspected, and after blood cultures have been taken, broad spectrum intravenous antibiotics should be administered until the results of the cultures and sensitivities is known, then a more specific antibiotic can be commenced (Prendergast, 2005). Prosthetic valve and pacemaker endocarditis, which is more common in the elderly requires 4-6 weeks of intravenous antibiotics, as well as removal of the prosthesis if possible (Prendergast, 2005). Repeat valve surgery is recommended in early prosthetic valve endocarditis. Surgery can be life saving in cases of IE and has been shown to be of benefit in suitable elderly patients. Often elderly patients are more unwell with multiple comorbidities and therefore may be deemed unsuitable for surgery (Prendergast, 2005). In one study (Di Salvo et al, 2003) surgery was performed only slightly less frequently than in younger patients and the operated group had a lower mortality. Of course this may reflect the fact that the patients suitable for surgery are generally fitter. Elderly patients may also refuse surgery. In a recent study of 961 patients with endocarditis in Spain (Ramírez-Duque, 2011) significantly fewer elderly patients underwent cardiac surgery (Table 1). The three main indications for surgery are heart failure, uncontrolled infection, and prevention of embolic events (European Society of Cardiology, 2009). In the Spanish study (Ramírez-Duque, 2011), compared with medical treatment, surgery showed lower mortality in the younger patients (less than 65 years), but a high mortality was observed with both medical and surgical treatment in the elderly (over 65 years). Overall in Europe, surgery is undertaken in around $50 \%$ of patients with IE with long-term survival rates of around $70 \%$ (Prendergast and Tornos, 2010). Surgery is better undertaken early before cardiac tissue damage has occurred and there is a general deterioration in the patients condition. Delay in surgery may contribute to poor outcomes in older patients.

\section{Culture negative endocarditis in the elderly}

Culture negative endocarditis is particularly common in older patients. The definition of culture negative endocarditis is endocarditis which fulfils established diagnostic criteria for endocarditis, but at least three independent blood cultures are negative after seven days of incubation and subculturing (Raoult et al, 2005). A two year multicentre prospective study in Italy found that $25 \%$ of patients with a definite diagnosis of endocarditis by Duke criteria were culture-negative (Cecchi et al, 2004). Cultures are negative in endocarditis for three major reasons: i) previous administration of antibiotics; ii) inadequate microbiological techniques, or iii) infection with highly fastidious bacteria or non-bacterial pathogens (e.g. fungi). Risk factors for culture negative endocarditis include underlying valvular heart disease, presence of a pacemaker and exposure to fastidious organisms. HACEK organisms (Haemophilus aphrophilus; Actinobacillus actinomycetemcomitans; Cardiobacterium hominis; Eikenella corrodens and Kingella Kingae) were originally thought to be the most common cause. However, better laboratory techniques have now led to the more successful isolation of these organisms. In 
a prospective study of 348 patients with culture negative endocarditis 275 (79\%) aetiological agents were identified using serological tests, and polymerase chain reaction (PCR) techniques (Houpikian and Raoult, 2005). The commonest agents found were coxiella burnetti ( $Q$ fever) and bartonella species. Serology and PCR on blood samples or removed valves can therefore help considerably in identifying fastidious organisms. Fungi are particularly common pathogens in early prosthetic valve endocarditis (Thuny et al, 2010). Clinically if it is not possible to identify the aetiological agent then treatment may have to be directed either at the most likely source if the patient has already been on antibiotics, or as broad spectrum as possible while closely monitoring clinical response. The long-term prognosis of negative blood culture IE in the elderly is similar to patients with positive blood cultures (Peréz de Isla et al, 2007). A specific form of culture negative endocarditis can occur in older people and cause diagnostic uncertainty. Non-bacterial thrombotic endocarditis (NBTE), or marantic endocarditis, is a rare condition associated with cancer and other illnesses where there is an increased thrombotic tendency, for example septicaemia (Clough et al, 2010). Clinical features of NBTE are very small, multiple valvular vegetations which may be only visible on TOE and multiple small, medium and large disseminated emboli in patients with an underlying cause for NBTE, and multiple negative blood cultures and serology. NBTE, unlike IE, may benefit from anticoagulation, but the outlook is poor, usually because of the underlying cause.

\section{Complications and outcomes of infective endocarditis in the elderly}

Complications of infective endocarditis can be categorised as:

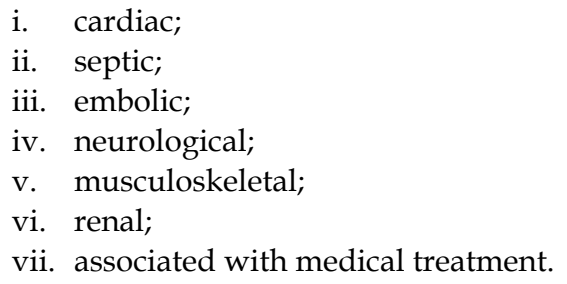

Cardiac complications are the most common complication in older patients. The most common of these is heart failure which is also the most common cause of death in IE. The usual cause of heart failure is infection-induced valvular damage for which cardiac surgery may be lifesaving. Embolisation seems less common in older people (Selton-Suty, 1997), but can occur resulting in stroke, splenic or renal infarction or myocardial infarction. The risk of embolisation is reduced by prompt antibiotic therapy. Apart from embolic stroke, other neurological complications include brain abscesses, seizures, meningitis and encephalitis. Renal failure may result from renal infarction, but also from glomerulonephritis and rarely renal abscesses. Musculoskeletal complications include vertebral osteomyelitis or discitis and septic arthritis. Finally, older patients with IE can develop complications associated with prolonged antibiotic treatment - for example ototoxicity and nephrotoxicity. It is widely accepted that age is an independent predictor of mortality in IE (Durante-Mangoni et al, 2008). Other factors associated with poor outcome are listed in Table 3 and include diabetes, significant comorbidities, heart failure and echocardiographic findings of poor left 
ventricular function, severe valve regurgitation and large vegetations. However, prognostic predictions should be made with caution in individual patients and many of these factors may be correctable with surgery.

\section{Prevention of endocarditis in the elderly}

It has previously been recommended that antibiotic prophylaxis should be given to the majority of patients with congenital and valvular heart disease before any dental or surgical procedure. However, this recommendation has now been narrowed to only high risk patients, including patients with prosthetic heart valves or with a previous history of IE and only for high risk procedures. High risk procedures include dental procedures that involve manipulation of gingival tissue, or the peri-apical region of the teeth, or perforation of the oral mucosa and also procedures in patients with ongoing gastrointestinal or genito-urinary infections. Interestingly, the NICE guidelines for England and Wales do not advocate antibiotics, even for high risk patients undergoing dental procedures (Chambers et al, 2011). This is because of lack of convincing trial evidence for antibiotic prophylaxis, even in this high risk group, and the risk of anaphylaxis with antibiotics and the potential development of antibiotic resistance. However, this is contrary to the European guidelines (European Society of Cardiology, 2009) and the usual practice of most clinicians who are influenced by the high mortality rate of high risk patients if they develop endocarditis, even though it may be a rare complication.

Older age Prosthetic valve endocarditis Diabetes Comorbidity (frailty, renal or pulmonary disease) Complications

- heart failure

- renal failure

- stroke

- $\quad$ septic shock Infecting organisms

- $\quad$ staphylococcus aureus

- fungi

- gram negative bacilli Echocardiographic findings

- $\quad$ large vegetations

- pulmonary hypertension

- periannular complications

- $\quad$ poor left ventricular ejection fraction

- $\quad$ severe left sided valve regurgitation or severe prosthetic dysfunction

Table 3. Predictors of poor outcome in older patients with infective endocarditis

\section{Conclusion}

IE is a very important and atypical illness in older people. Firstly, its incidence seems to be increasing because of the increase in degenerative valvular disease and the increasing use of cardiac prosthetic devices. Secondly, it can present in a variety of different ways depending 
on the underlying cardiac disease and the microorganisms involved and the underlying patient comorbidities and resistance to infection. It therefore requires a collaborative approach involving physicians, geriatricians, cardiologists, cardiac surgeons and microbiologists. Thirdly, the evidence for its clinical manifestations, treatment and prognosis comes from clinical case series rather than from clinical trials or meta-analyses. Five important case series predominantly from Europe have been published and are summarised in Table 1, comparing older patients with younger patients with IE. Consistently older patients tend to have a higher mortality, are less likely to have surgery and more likely to have prosthetic devices and be infected with bacteria from the gut or urinary tract. Older people are more likely to present insidiously with smaller vegetations and less embolic manifestations. It can be argued that IE is a completely different disease in the older person and deserves a different, more aggressive approach in both treatment and prevention because of its high morbidity and mortality.

\section{References}

Aronow, W.S., Koenigsberg, M., Kronzon, I. et al (1990). “Association of mitral annular calcification with new thromboembolic stroke and cardiac events at 39-month follow up in elderly patients." Am J Cardiol; 65: 1511-1512. Cecchi, E., Forno, D., Imazio, M., Migliardi,

A., Gnavi, R., Dal Conte, I. \& Trinchero, R. (2004). “New trends in the epidemiological and clinical features of infective endocarditis: results of a multicenter prospective study." Ital Heart ;J Apr;5(4): 249-56.

Chambers, J.B., Shanson, D., Hall, R., Pepper, J., Graham V. \& McGurk, M. (2011). "Antibiotic prophylaxis of endocarditis: the rest of the world and NICE." J R Soc Med; 104: 138-140.

Clough, H., George, J. \& Duncan, A. (2010). "Psychosis due to non-bacterial thrombotic endocarditis." Age and Ageing; 39: 276-277.

Delahye, F., Rial, M.O., de Gevigney, G., Ecochard, R. \& Delaye, J. (1999). "A critical appraisal of the quality of the management of infective endocarditis." J Am Coll Cardiol; 33: 788-793.

Di Salvo, G., Thuny, F., Rosenberg, V., Pergola, V., Belliard, O., Derumeaux, G., Cohen, A., Larussi, D., Giorgi, R., Casalta, J.P., Caso, P. \& Habib, G. (2003). “Endocarditis in the elderly: clinical echocardiographic, and prognostic features." European Heart Journal; 24: 1576-1583.

Dhawan, V.K. (2002). "Infective Endocarditis in Elderly Patients." Clinical Infectious Diseases; 34 (15 March): 806-812.

Durante-Mangoni, E., Bradley, S., Selton-Suty, C., Gripodi, M.F., Barsic, B., Bouza, E., Cabell, C.H., de Oliveira Ramos, A.I., Fowler, V., Hoen, B., Konecny, P., Morena, A., Murdoch, D., Pappas, P., Sexton, D.J., Spelman, D., Tattevin, P., Miró, J.M., van der Meer, J.T.M. \& Utili, R. (2008). "Current Features of Infective Endocarditis in Elderly Patients." Arch Intern Med; 168(19): 2095-2103.

European Society of Cardiology' (2009). "Guidelines on the prevention, diagnosis, and treatment of infective endocarditis (new version 2009)." European Heart Journal; 30: 2369-2413. 
High, K.P., Bradley, S., Loeb, M., Palmer, R., Quagiarello, V. \& Yoshikawa, T. (2005). “A New Paradigm for Clinical Investigation of Infectious Syndromes in Older Adults: Assessment of Functional Status as a Risk Factor and Outcome Measure." Clinical Infectious Diseases; 40: 114-122.

Hoen, B., Alla, F., Selton-Suty, C., Beguinot, I., Bouvet, A., Briancon, S., Casalta, J.P., Danchin, N., Delahaye, F., Etienne, J., LeMoing, V., Leport, C., Mainard, J.C., Rulmy, R. \& Vandenesch, F. (2002). "Changing profile of infective endocarditis: results of a 1-year survey in France." JAMA; 288: 75-81.

Houpikian, P. \& Raoult, D. (2005). “Blood culture-negative endocarditis in a reference center: etiologic diagnosis of 348 cases." Medicine (Baltimore), May; 84(3): 162173.

Iung, B., Baron, G., Butchart, E.G., Delahaye, F., Gohlke-Barwolf, C., Levang, O.W., Tornos, P., Vanoverschelde, J.L., Vermeer, F., Boersma, E., Ravaud, P. \& Vahanian, A. (2003). "A prospective survey of patients with valvular heart disease in Europe: the Euro Heart Survey on Valvular Heart Disease. Eur Heart J; 24: 1231- 1243.

Mambo, W.C., Silver, M.D., Brunsdon, D.F.V. (1978). “Bacterial endocarditis of the mitral valve associated with annular calcification." Can Med Assoc J; 119: 323-326.

Peréz de Isla, L., Zamorano, J., Lennie, V., Vázquez, J., Ribera, J.M. \& Macaya, C. (2007). “Negative Blood Culture Infective Endocarditis in the Elderly: Long-Term Follow Up." Gerontology; 53: 245-249.

Prendergast, B.D. (2006). "The changing face of infective endocarditis.". Heart; 92: 879-885.

Prendergast, B.D. \& Tornos, P. (2010). "Surgery for Infective Endocarditis: Who and When?" Circulation; 121: 1141-1152.

Ramírez-Duque, E., Carcía-Cabrera, R., Ivanova-Georgieva, R., Noureddine, M., Lomas, J.M., Hidalgo-Tenorio, A., Plata, J., Gálvez-Acebal, J., Ruíz-Morales, J., de la TorreLima, J., Reguera, J.M., Martínez-Marcos, F.J. \& de Alarcón, A. (2011). “Surgical treatment for infective endocarditis in elderly patients." Journal of Infection; 63: 131138.

Raoult, D., Casalta, J.P., Richet, H., Khan, M., Bernit, E., Rovery, C., Branger, S., Gouriet, F., Imbert, G., Bothello, E., Cocllart, F. \& Habib, G. (2005). “Contribution of systematic serological testing in diagnosis of infective endocarditis." J Clin Microbiol., Oct:43(10): 5238-5242.

Remadi, J.P., Nadji, G., Goissen, T., Zomvuama, N.A., Sorel, C. \& Tribouilloy, C. (2009). "Infective endocarditis in elderly patients: clinical characteristics and outcome." Eur J Cardiothorac Surg; 35: 123-129.

Roberts, W.C., Perloff, J.K. (1972). "Mitral valvular disease. A clinicopathologic survey of the conditions causing the mitral valve to function normally." Ann Intern Med; 77: 939975.

Selton-Suty, C., Hoen, B., Grentzinger, A., Houplon, P., Maignan, M., Juilliére, Y., Danchin, N., Canton, P. \& Cherrier, F. (1997). "Clinical and bacteriological characteristics of infective endocarditis in the elderly." Heart; 77: 260-263.

Thuny, F., Fournier, P.E., Casalta, J.P., Gouriet, F., Lepidi, H., Riberi, A., Collart, F., Habib, G. \& Raoult, D. (2010). “Investigation of blood culture-negative early 
prosthetic valve endocarditis reveals high prevalence of fungi." Heart, May;96(10): 743-747.

Vahanian, A. (2003). "The growing burden of infective endocarditis in the elderly." European Heart Journal; 24: 1539-1540. 


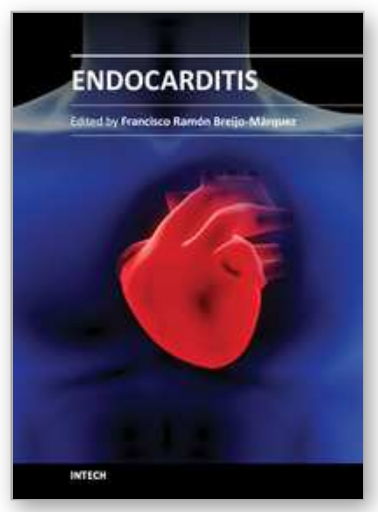

\author{
Endocarditis \\ Edited by Prof. Francisco Ramón Breijo-Márquez
}

ISBN 978-953-307-901-1

Hard cover, 152 pages

Publisher InTech

Published online 20, January, 2012

Published in print edition January, 2012

Endocarditis is a disease that occurs as a result of the inflammation of the endocardium. It is an inflammatory process located in the inner lining of the cardiac chambers and native or prosthetic valves. It is characterized by colonization or invasion of the heart valve vegetations composed of platelets forming, fibrin and microcolonies of microorganisms, and occasionally of inflammatory cells. Other structures may also be affected, such as the interventricular septum, chordae tendineae, the mural endocardium or even intra-cardiac implants. The book covers, with scientific rigour, the most prevalent causes and current treatments of endocarditis, as well as the cases when the organs remote from the heart are affected by this disease.

\title{
How to reference
}

In order to correctly reference this scholarly work, feel free to copy and paste the following:

Lucy Miller and Jim George (2012). Infective Endocarditis in the Elderly, Endocarditis, Prof. Francisco Ramón Breijo-Márquez (Ed.), ISBN: 978-953-307-901-1, InTech, Available from:

http://www.intechopen.com/books/endocarditis/infective-endocarditis-in-the-elderly

\section{INTECH}

open science | open minds

\section{InTech Europe}

University Campus STeP Ri

Slavka Krautzeka 83/A

51000 Rijeka, Croatia

Phone: +385 (51) 770447

Fax: +385 (51) 686166

www.intechopen.com

\section{InTech China}

Unit 405, Office Block, Hotel Equatorial Shanghai

No.65, Yan An Road (West), Shanghai, 200040, China

中国上海市延安西路 65 号上海国际贵都大饭店办公楼 405 单元

Phone: +86-21-62489820

Fax: +86-21-62489821 
(C) 2012 The Author(s). Licensee IntechOpen. This is an open access article distributed under the terms of the Creative Commons Attribution 3.0 License, which permits unrestricted use, distribution, and reproduction in any medium, provided the original work is properly cited. 